\title{
Na Boca do mundo: A paisagem de Antônio Pitanga1
}

\section{Leonardo Soares Young}

Pontifícia Universidade Católica do Rio de Janeiro - PUC-Rio

Departamento de Comunicação Social - Bacharelado em Cinema

\section{Resumo}

Este artigo aborda aspectos da memória a partir do filme Na Boca do Mundo (1979), dirigido por Antônio Pitanga, e realizado durante um período de intensa produção cinematográfica no Brasil, parte do projeto nacional-popular da Empresa Brasileira de Filmes S/A (Embrafilme). Assim como o contexto histórico do filme, analisaremos aspectos narrativos - buscando compreender o retrato das relações inter-raciais abordadas nesta obra - e a representação visual de Atafona por Pitanga. A pesquisa analisa ainda a recepção crítica do filme e sua influência no cinema brasileiro. Investigando essas relações e suas dinâmicas há uma maior compreensão dos símbolos e representações desta obra, bem como a necessidade de sua preservação e revisitação.

\section{Palavras-chave}

Cinema brasileiro, memória, Na Boca do Mundo, Antônio Pitanga, Atafona.

\section{Introdução}

O objetivo deste artigo é examinar a realização e a memória do filme Na Boca do Mundo $(1979)^{2}$, de Antônio Pitanga, no contexto histórico da cinematografia brasileira, bem como a autenticidade artística e simbólica do filme, além da relação da obra com sua locação principal, Atafona. Reconstruir interpretações teóricas e analisar aspectos sobre recepção crítica permitem não somente compreender a representatividade do filme, mas também entender suas singularidades. De início, o trabalho pretende examinar brevemente a trajetória do cinema popular no Brasil entre as décadas de 1960 e 1970 principalmente sob influência da Embrafilme, entre os anos de 1974 e 1979 - assim como as reflexões artísticas e as influências destes filmes na construção de uma imagem nacional. A análise de tal trajetória introduz o momento histórico da produção de $\mathrm{Na}$

\footnotetext{
1 Artigo adaptado de monografia de graduação em Cinema, orientada pela professora Carmem Petit e apresentada em julho de 2020.

2 Alguns registros indicam o filme a partir de seu ano de produção, 1978. Nesta pesquisa, no entanto, levaremos em conta o ano de lançamento, 1979. Dados da Cinemateca Brasileira. Disponível em: http://bases.cinemateca.gov.br/cgi-

bin/wxis.exe/iah/?IsisScript=iah/iah. $x i s \& b a s e=F I L M O G R A F I A \& l a n g=p \& n e x t A c t i o n=I n k \& e x p r S e a r c h=I D=02497$ $6 \&$ format=detailed.pft\#1. Acesso em 21/04/2020
} 
Boca do Mundo para, em seguida, apresentar suas implicações no cinema brasileiro. Nesse sentido, também serão contemplados elementos narrativos do filme, a fim de compreender seu aspecto crítico e sua estrutura diegética.

Para Nora, lugares de memória são locais - materiais ou abstratos - conferidos de sentido simbólico em seu registro e no que os transcende. "Mesmo um lugar de aparência puramente material, como um depósito de arquivos, só é lugar de memória se a imaginação o investe de aura simbólica" (NORA, 1993, p. 21). A partir da relação estabelecida pelo autor, será analisada a representação histórica e da memória de $\mathrm{Na}$ Boca do Mundo para Atafona, local cuja configuração espacial mudou drasticamente desde então, por influência de fenômenos naturais.

Com o intuito de investigar as construções narrativas do filme, suas simbologias e correlações históricas, buscaremos referências em autores como Benedict Anderson, Roberto DaMatta e Robert Stam. Serão consideradas as relações sociais e espaciais estabelecidas pelo filme em sua locação. O trabalho irá examinar os aspectos destes lugares de memória e suas conexões antropológicas a partir de conceitos do autor Pierre Nora. Investigar tais relações nos permite compreender a repercussão e a representatividade de $\mathrm{Na}$ Boca do Mundo na historiografia do cinema brasileiro.

Durante a década de 1960, nota-se uma mudança significativa na concepção ideológica do cinema no Brasil e em suas formas de realização. O Cinema Novo, movimento artístico dominante à época, é representado por cineastas como Nelson Pereira dos Santos, Glauber Rocha e Ruy Guerra (XAVIER, 2001). Os filmes desses realizadores estavam focados, principalmente, na compreensão das questões sociais, raciais e de classe no país, em um período de transformação política (na iminência do golpe civilmilitar, em 1964). Influenciados pelos princípios estéticos do neorrealismo italiano, os realizadores desenvolvem um cinema de ideal revolucionário, engajado politicamente à esquerda, atento às raízes culturais e regiões marginalizadas do país. Vidas Secas (1963), Deus e o Diabo na Terra do Sol (1964) e Os Fuzis (1964) são frequentemente apontados como filmes canônicos do período inicial do Cinema Novo e, sobretudo, como referências fundamentais da linguagem "cinemanovista".

Com o início dos anos 1970, surgem diferentes manifestações artísticas e ideais estéticos no cinema nacional. A partir desse período, há um aumento quantitativo na produção cinematográfica e o surgimento de novas formas de compreensão da realidade social brasileira, influenciadas, sobretudo, pelo Tropicalismo (XAVIER, 2001). O movimento do 
Cinema Marginal, introduzido por filmes como A Margem (1967), O Bandido da Luz Vermelha (1968), O Anjo Nasceu (1969) e Bang Bang (1971) transforma o conceito de autoria presente nas obras dos "cinemanovistas", com uma redefinição de linguagem e estética. Os filmes de Ozualdo Candeias, Rogério Sganzerla, Júlio Bressane, Andrea Tonacci e de outros cineastas contestavam a ideia de um cinema culto, do universo rural e do interior brasileiro consolidado pelo Cinema Novo. Surgia uma proposta ainda autoral, mas iconoclasta - influenciada por movimentos como a Nouvelle Vague francesa, o cinema underground norte-americano e focada no espaço marginalizado das grandes cidades.

O cinema brasileiro da segunda metade dos anos 1970 apresenta filmes populares, com números expressivos de bilheteria e aclamação do público. Após a criação da estatal Empresa Brasileira de Filmes S/A (Embrafilme), em 1969, o regime militar passa a investir na divulgação e produção cinematográfica do país. Inicia-se o projeto estatal de um cinema nacional-popular, de eficiência mercadológica (JORGE, 2002). A partir desse momento, o cinema autoral perde espaço para um cinema de indústria, com o número de produções anuais crescendo exponencialmente durante o período de apoio da estatal.

Entre 1974 e 1979, a Embrafilme vive sua "Era de ouro", dirigida pelo cineasta Roberto Farias. Neste período são realizados alguns dos filmes mais populares da história do cinema brasileiro, como Dona Flor e Seus Dois Maridos (1976), de Bruno Barreto, que ultrapassa a marca de 11 milhões de espectadores, e $A$ Dama do Lotação (1978), de Neville d'Almeida, assistido por 6,5 milhões de pessoas (GATTI, 2008).

No período de maior sucesso comercial da Embrafilme, cineastas identificados com o Cinema Novo - muitas vezes privilegiados na aprovação de financiamentos - ainda realizavam filmes de repercussão popular, como Xica da Silva (1976), de Cacá Diegues. Nesse contexto, o ator Antônio Pitanga, presente em obras fundamentais do Cinema Novo e Marginal como Barravento (1962), Ganga Zumba (1963), A Mulher de Todos (1969), Jardim de Guerra (1970), desenvolve um argumento com Diegues que dá origem ao roteiro de Leopoldo Serran (Dona Flor e Seus Dois Maridos). Em sua estreia como diretor, Pitanga apresenta Na Boca do Mundo (1979), produzido pelo próprio realizador, pela Lente Filmes e coproduzido pela Embrafilme.

Protagonizado por Antônio Pitanga, ao lado de Norma Bengell e Sibele Rúbia, o filme está centrado na história de um triângulo amoroso em Atafona, vila de pescadores no litoral da região Norte Fluminense. Na essência da obra, está o desenvolvimento das 
relações entre estes três personagens, marcado por questões raciais e de classe. Mesmo ao revisitar temas do Cinema Novo e aspectos clássicos do melodrama, Na Boca do Mundo será, neste artigo, observado enquanto obra singular na história do cinema brasileiro.

O artigo será dividido em quatro parte. A primeira baseia-se na compreensão do contexto histórico da cinematografia brasileira durante as décadas de 60 e 70 . Na segunda, a construção da narrativa e dos personagens de $\mathrm{Na}$ Boca do Mundo será contemplada, assim como a representatividade das relações interraciais no cinema nacional. A terceira parte irá analisar a expressão estética e a memória da locação do filme, Atafona. Na quarta, nos debruçaremos sobre a recepção, preservação e influência do filme de Antônio Pitanga na história do cinema brasileiro.

\section{Cinema nacional-popular e a "Era de Ouro" da Embrafilme}

Para Anderson, a nação enquanto comunidade imaginada é uma criação social formada por um imaginário coletivo - de imagens, símbolos, signos - que mantém certa homogeneidade em sua essência (ANDERSON, 2008). Torna-se possível, a partir desses elementos análogos, estabelecer relações de identificação, mesmo em diferentes culturas e espectros sociais. A estruturação de tal imaginário revela essas imagens em seus processos afirmativos, de contestação e crítica, no intuito de formar uma identidade nacional de relativa unidade. Deste modo, nota-se a constante elaboração de ideias representativas (aqui, especificamente da produção cultural) a serem integradas à noção geral do pertencimento a uma nação.

Enquanto produtor de imagens, o cinema envolve-se neste processo como parte efetiva da construção e difusão de uma imagem nacional. É possível compreender, portanto, que a disputa de imagens representativas constrói um olhar pelo qual um povo percebe a própria nação. Nesse sentido, analisamos a construção de uma autoimagem nacional brasileira - via produção artística e intervenção estatal - diante da formação de um cinema nacional-popular moderno nos anos 60 e 70.

Em 1969, sob a vigência do Ato Institucional no 5 - marco inicial do período mais repressor da ditadura militar - é fundada a Empresa Brasileira de Filmes S/A (Embrafilme), órgão subordinado ao Instituto Nacional de Cinema (INC) e ao Ministério de Educação e Cultura (MEC). Ao observar o decreto-lei publicado pelo Governo Federal 
em 12 de setembro de 1969, é possível compreender algumas das principais motivações socioeconômicas para a criação da estatal.

Art $2^{\circ}$ A EMBRAFILME tem por objetivo a distribuição de filmes no exterior, sua promoção, realização de mostras e apresentações em festivais, visando à difusão do filme brasileiro em seus aspectos culturais artísticos e científicos, como órgão de cooperação com o INC, podendo exercer atividades comerciais ou industriais relacionadas com o objeto principal de sua atividade. (BRASIL, 1969) ${ }^{3}$

No fim da década de 60, filmes brasileiros eram exibidos e exaltados em festivais internacionais de cinema. Havia interesse do regime militar, portanto, em administrar a produção cinematográfica para controlar a imagem externa do Brasil. Inicialmente, a classe cinematográfica repudiou a criação da Embrafilme, por entender que o regime militar pretendia monitorar e censurar filmes. Neste processo, cineastas e produtores que não foram consultados para a fundação da estatal - viam-se alheios ao projeto de fomento de um cinema brasileiro popular. Nos primeiros anos da Empresa, a direção geral e os cargos principais eram cedidos apenas aos militares ou pessoas próximas.

Em 1974, a nomeação do cineasta Roberto Farias como diretor geral da Embrafilme dá início ao período de maior estreitamento das relações entre cinema e Estado. A gestão de Farias (1974-1979) amplia a atuação da empresa até a produção, financiamento, distribuição e exibição de filmes nacionais. É neste período, uma "Era de ouro" da Embrafilme, que a indústria cinematográfica brasileira cresce consideravelmente e alcança uma administração absoluta do produto fílmico.

Como resultado das políticas públicas da gestão Farias, o número de lançamentos por ano no cinema brasileiro também apresenta um crescimento notável. Segundo dados recolhidos por Gatti (2008), o número de produções anuais chega a um recorde de 100 filmes, em 1978. Neste período, nota-se a consolidação do projeto de filmes populares financiado pelo Estado e voltados, principalmente, para o retorno mercadológico superando a condição produtiva historicamente sazonal do cinema brasileiro.

Enquanto co-produtora, a Embrafilme priorizava o apoio a filmes de orçamento médio, supondo que a qualidade final do produto seria resultado da quantidade. A empresa entrava como coprodutora do filme, assumindo os riscos financeiros de exibição e distribuição do produto final. Para Amâncio, esse formato "caracterizou também o

\footnotetext{
3 BRASIL. Decreto-lei no 862 de 12 de setembro de 1969. Autoriza a criação da Empresa Brasileira de Filmes Sociedade Anônima (EMBRAFILME), e dá outras providências. Disponível em: http://www.planalto.gov.br/ccivil 03/decreto-lei/1965-1988/Del0862.htm Acessado em 26/06/2020
} 
aparecimento de um cinema híbrido, que, embora sem chancelas dirigistas, se localizou entre as perspectivas do mais arrojado cinema autoral e do mais inconsistente cinema comercial." (AMÂNCIO, 2007, p. 182).

Para além do êxito comercial do cinema brasileiro, há uma gradual transformação na maneira de retratar figuras marginalizadas da sociedade. Desde a primeira fase do Cinema Novo, nota-se a presença do homem negro como metáfora do povo brasileiro, do trabalhador, do pobre, do oprimido, do migrante, do favelado. Este aspecto está presente desde Rio, Zona Norte (1957) e é ressaltado por filmes como Aruanda (1960), Bahia de Todos os Santos (1960), A Grande Feira (1961), Cinco Vezes Favela (1962). Como apontam Carvalho e Domingues (2017), a questão racial nos filmes da década de 60 , muitas vezes, limita-se a sintetizar as condições de desigualdade social no país em poucas figuras. "(...) a questão do negro ficaria diluída nas contradições sociais da nação, não assumindo, assim, primazia para os cineastas daquele movimento" (CARVALHO; DOMINGUES, 2017, p. 387).

Neste período de produção híbrida citado por Amâncio, nota-se a chegada de novas vozes na produção cinematográfica, como realizadores que fogem do padrão racial e de classe no cinema brasileiro - predominantemente formado por homens brancos oriundos da classe média e classe média alta. Senna (1979) aponta que a compreensão reducionista das imagens raciais no Brasil seria alterada a partir do surgimento de realizadores negros no cinema nacional ${ }^{4}$.

A modificação deste panorama nos últimos três anos é sutil, se levarmos em conta a gigantesca produção de filmes no Brasil (cerca de 100 longas e 200 curtas-metragens por ano) e a discriminação racial disseminada, em estado crônico, nas elites intelectuais. Um dos pontos que pode tornar menos sutil esta modificação é o surgimento de diretores negros - que nunca ocorrera antes. (SENNA, 1979, p. 225)

O autor aponta, especificamente, para uma nova geração composta por três diretores: Zózimo Bulbul, Alma no Olho (1974); Waldir Onofre, As Aventuras Amorosas de um Padeiro (1975) e Antônio Pitanga, Na Boca do Mundo (1979). Em seus diferentes temas e concepções artísticas, os filmes dirigidos por Bulbul, Onofre e Pitanga representam novos olhares na cinematografia brasileira e interpretações autênticas de temas recorrentes nas décadas de 60 e 70.

\footnotetext{
${ }^{4}$ Apesar de não se enquadrar nesta geração de cineastas, Compasso de Espera (1973), de Antunes Filho, é um filme que subverte o retrato típico das relações interraciais no Brasil. O protagonista Jorge (Zózimo Bulbul), é um intelectual negro de classe média - figura incomum até então.
} 


\title{
3. Na Boca do Mundo: linguagem, símbolos e narrativas
}

O argumento de Na Boca do Mundo, desenvolvido por Antônio Pitanga e Cacá Diegues apresenta três figuras principais: um homem negro (Pitanga), uma mulher "mulata" (Sibele Rúbia) e uma branca (Norma Bengell). Em entrevista, Pitanga, diretor e protagonista, afirma sua intenção de analisar as relações inter-raciais no Brasil através destes personagens e discutir temas pouco representados no cinema nacional até então.

\begin{abstract}
É como se nós fôssemos nos conhecer e nos digladiarmos (...) para saber pra onde nós vamos. Se vamos por aqui ou por aqui. Porque a crítica contra o mulato, a mulata era muito grande $(. .$.$) e$ havia uma marca que nos esvaziava naquele momento, naquela época da década de 50, 60 e até na década de 70, que era o surgimento da mulata. A mulata era a tal, mas o negro... Quer dizer, o processo do preconceito era gritante. O show business, o glamour em relação a mulata era muito grande... E se ficava assim: Se a mulata era a tal, por que esses negros tão reclamando do preconceito, que não pode, não tem chance? (FUNDAÇÃO CULTURAL PALMARES, 2006).
\end{abstract}

Uma questão importante na discussão apontada pelo realizador era a visibilidade das mulheres mulatas entre os anos 1950 e 1970, ao mesmo tempo em que se mantinha um apagamento da presença de atores negros no cinema e na televisão. Penna comenta as representações destas figuras femininas, desde o teatro de revista até as dançarinas de shows populares. "(...) A mestiçagem desde o descobrimento esteve associada à sensualidade e sexualidade, fruto de uma ocupação eminentemente masculina" (PENNA, 2016. p. 100).

A evidência midiática das mulatas nas décadas de 60 e 70 remete à romantização e erotização das mulheres negras e indígenas em obras literárias do século XIX, explorada por autores como José de Alencar. Desde então, nota-se o protagonismo dessas mulheres e dos homens brancos em um suposto "encontro fundador" da nação, presente nas narrativas populares. Lapera indica o esvaziamento das demais figuras brasileiras na construção representativa deste encontro. "Além disso, o apagamento dos homens índios e negros e das mulheres brancas na produção de uma retórica erótica (...) seria mais um índice revelador dessa mestiçagem a ser difundida durante a ditadura militar" (LAPERA, 2013, p. 107).

Desde os anos 1930, por meio de autores como Gilberto Freyre, sustenta-se a ideia de uma construção diversa e harmônica da sociedade brasileira, no sentido de positivar a miscigenação, compreendendo-a enquanto solução do processo civilizatório. A partir deste pensamento, surge como ideia fundadora de um novo Brasil, o mito da 
"democracia racial". No entanto, esta visão conciliadora da mestiçagem e, ainda, da sexualidade inauguradora do país, seria contestada por diversos artistas e autores a partir da segunda metade do século - principalmente nos anos 60 e 70 (PINTO, 2009).

Em Na Boca do Mundo, por exemplo, Pitanga questiona a suposta integração social pacífica por meio das trocas culturais e afetivo-sexuais, uma vez que os personagens põem em xeque a positivação da mestiçagem e a visão conciliadora dessas relações. $O$ processo de apagamento do homem negro abordado pelo diretor em sua entrevista fazse presente no protagonista, Antônio, manipulado e descartado pelas personagens de Norma Bengell e Sibele Rúbia.

O filme acompanha o relacionamento entre Antônio, Clarisse e Terezinha - com estas três figuras retratadas por meio de uma narrativa melodramática. Stam (2008) aponta para o recurso do melodrama como meio de representação recorrente dos conflitos étnicos no cinema brasileiro. Os dilemas morais presentes neste formato, para o autor, permitem a revelação de estereótipos raciais e seus conflitos de forma explícita. Desse modo, Pitanga constrói um triângulo amoroso representando três figuras centrais do imaginário brasileiro, de forma que estes personagens contestem os ideais consolidados da "democracia racial".

Antônio e Terezinha vivem em Atafona, uma vila de pescadores ameaçada pelo avanço do mar, marcada pela destruição e pela pobreza. Enquanto Antônio trabalha em um posto de gasolina, sua noiva, Terezinha, vende caranguejos à beira da estrada. Desde o início, a personagem de Sibele Rúbia pretende ascender socialmente, deixando Atafona para viver na cidade vizinha, Campos, ou até mesmo no Rio de Janeiro. Antônio atende às demandas da noiva e se qualifica, por meio de um curso de mecânico por correspondência, para conseguir um emprego e buscar melhores condições de vida em outra cidade.

Clarisse chega à Atafona em busca de refúgio a uma vida vazia, cujo sentido foi perdido após uma separação. Em sua primeira cena, a personagem expressa um descontentamento com a própria existência que a fez considerar o suicídio. A partir do envolvimento com Antônio, Clarisse sente-se amparada e encontra uma possibilidade de superar a dor e a tristeza, na medida em que ela romantiza a "simplicidade" do povo atafonense e, sobretudo, do personagem de Pitanga. "Um homem que não foi assaltado pelo delírio da civilização. Belo. Selvagem. Dorme quando tem sono, come quando tem fome (...). Um ser estranho para mim que vivi num mundo de homens sem alma". 
A relação entre estes dois personagens passa a ser intermediada por Terezinha, que, ao descobrir a traição, obriga o noivo a continuar encontrando a amante e fazer o necessário para garantir a ida deles à cidade grande, inclusive engravidar Clarisse e chantageá-la. "Faça um filho nela e depois explore isso. "Já pensou, uma branca da sociedade tendo um filho crioulo? (...) Ela faria qualquer coisa para esconder isso", diz Terezinha. Apesar de relutante, Antônio obedece a noiva e mantém sua relação com Clarisse, que Ihe jura amor, apesar de tratá-lo ora como empregado, ora como amante.

O protagonista alterna sua atenção entre Terezinha e Clarisse, entregando-se para ambas, atendendo às necessidades afetivas, sexuais, materiais e subjetivas que elas apresentam. Visto como "belo e selvagem" pela amante e como "fraco" pela noiva, Antônio se esforça em corresponder a expectativas e desejos que não são próprios dele. O tema musical do filme, "Amante Amado", cantado por Caetano Veloso, acompanha o protagonista em seu caminho trágico, desde as cenas mais prosaicas às mais catárticas. Nesse sentido, a letra da canção representa Antônio quase que literalmente, expressando sua condição de adorado e, ao mesmo tempo, rejeitado: "Pois eu sou o seu escravo, amor. Pois eu sou o seu amante amado, amor".

DaMatta aponta os ideais de democracia racial como proposta totalizante de um Brasil harmônico, como visto por grande parte da sociedade, desde os escritos de Gilberto Freyre e, consequentemente, estabelecido como um referencial desde o início do século XX. "Durante muitos anos forneceu e ainda hoje fornece, o mito das três raças, as bases de um projeto político e social para o brasileiro (através da tese do branqueamento, como alvo a ser buscado)" (DAMATTA, 1987, p. 69). Este ideal faz-se presente em $\mathrm{Na}$ Boca do Mundo, materializado pela aliança entre Clarisse e Terezinha. Esta última, em busca de ascensão social, procura uma vida idealizada na cidade grande, amparada pela rica e culta Clarisse.

Com a confissão de Antônio - que revela o plano elaborado pela noiva - Clarisse sentese magoada e planeja uma vingança. No fim, ela mata o amante, utilizando o veneno que havia trazido para uso próprio. As últimas palavras do personagem de Pitanga são emblemáticas: "A senhora me matou". Ele retoma o tratamento formal, evidenciando a distância social que ela, em certas ocasiões, recusava. A sequência final mostra a partida de Clarisse, revigorada e pronta para retomar a vida longe daquele lugar. Antes de ir, ela propõe a Terezinha que ambas deixem Atafona juntas. 
Desse modo, ambas concluem o ciclo simbólico da exclusão proposto por Pitanga desde o princípio. Aqui, os conflitos raciais analisados pelo diretor resultam na aliança entre a mulher mulata e a branca às custas da vida do homem negro. O processo de apagamento mencionado anteriormente por Pitanga se materializa nesta narrativa, com o alinhamento dos interesses através de uma positivação da mestiçagem enquanto formadora de um todo social equilibrado.

\section{Atafona por Antônio Pitanga}

Atafona é um distrito do munícipio de São João da Barra, litoral norte do Rio de Janeiro. Antiga aldeia e porto de pescadores, o local tornou-se também um balneário, frequentado, sobretudo, pelos sanjoanenses e por veranistas da cidade vizinha, Campos dos Goytacazes. Desde os anos 1950, nota-se o surgimento de fenômenos naturais na região, como a erosão marítima. O processo erosivo intensificou-se a partir da década de 70, destruindo, até então, 15 ruas e mais de 400 casas. Área mais afetada pelo avanço do mar, o Pontal de Atafona - onde há o encontro entre o rio Paraíba do Sul e o Oceano Atlântico - abrigava a maior parte das construções.

Na Boca do Mundo, portanto, surge como representação de uma Atafona que já não existe, uma vez que a maioria dos espaços presentes no filme foi destruída pelo mar. Dentre as locações afetadas, destacam-se o Pontal, a Ilha da Convivência e a capela de Nossa Senhora dos Navegantes. Para além do sentido de registro espacial, o filme preserva a noção de memória do povo atafonense durante um período de transformações sociais significativas.

Para Nora, a memória é preservada, vivida coletivamente e transmitida por gerações, mas desenvolve uma dependência de dispositivos externos para evocar e perpetuar seu sentido ao longo do tempo. "Menos a memória é vivida do interior, mais ela tem necessidade de suportes exteriores e de referências tangíveis de uma existência que só vive através delas" (NORA, 1993, p. 14). A partir deste ponto, o autor sublinha a transformação da memória em história, mesmo que esta última seja uma reprodução imprecisa da primeira.

Nesse sentido, Nora apresenta o conceito do lugar de memória, lugares (materiais ou imateriais) envolvidos por uma "aura simbólica" e, necessariamente, objetos de um ritual. "O que os constitui é um jogo da memória e da história, uma interação dos dois 
fatores que leva a sua sobredeterminação recíproca" (1993, p. 22). Para o autor, estes lugares garantem a transferência de experiências sensoriais, culturais e de costumes de um grupo para outros, formando sentimentos de identidade e pertencimento. $O$ autor complementa:

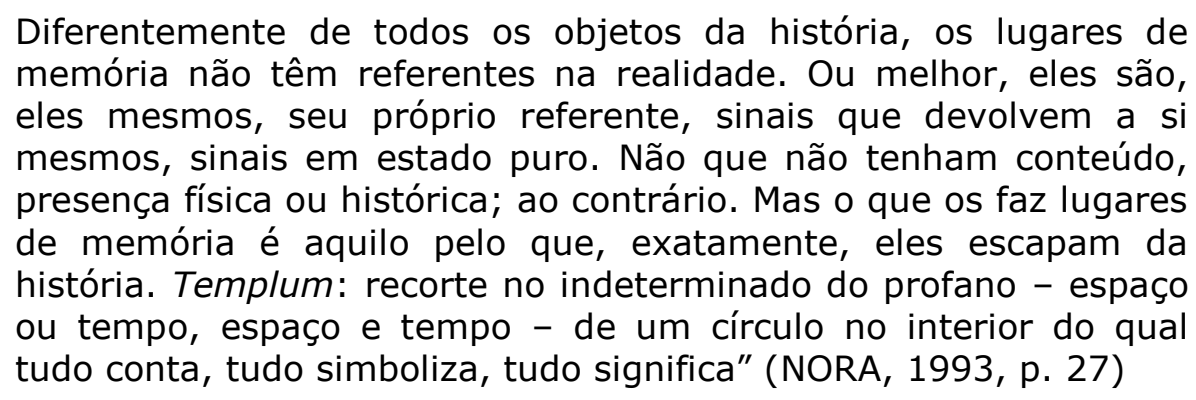

Diante deste conceito, compreendemos $\mathrm{Na}$ Boca do Mundo enquanto lugar de memória. O filme não existe apenas como registro histórico da destruição de Atafona ou da vida no local durante os anos 70 - há diversos estudos e materiais publicados em jornais e periódicos que examinam tais aspectos e suas consequências (BLASI CUNHA, 2007; GOMES, 2012). A obra de Pitanga, sempre que assistida, pode expressar novos sentidos para o espectador, seja de estranheza, seja de identificação.

Para além da percepção imediatista de uma paisagem tropical devastada pela natureza, o filme se aprofunda em um imaginário local. Em Na Boca do Mundo, Atafona é um lugar vivo, dotado de fragmentos do real e do simbólico - traços reforçados pela visão dos personagens. Desde o início do filme, há uma imersão na vida deste povo e de seus espaços. As locações evidenciam o processo de apagamento do espaço geográfico, bem como a preservação imagética de lugares simbólicos. Desse modo, sentidos da história e da memória do local são manifestados, representando a "sobredeterminação recíproca" descrita por Nora.

A primeira cena de $\mathrm{Na}$ Boca do Mundo, em que Antônio bebe e joga cartas escondido de Terezinha, foi gravada em um lugar extinto no Pontal, o bar Esteirinha - onde funcionava um bordel disfarçado, até 1975. Outro local destruído pelo mar é a capela de Nossa Senhora dos Navegantes, sempre exibida quando Terezinha está à beira da estrada, vendendo caranguejos. Para muitos pescadores da região, esta capela explica a devastação de Atafona, uma vez que foi construída, ao fim dos anos 50, de costas para o mar. "Segundo eles, o mar está avançando em Atafona devido a um castigo divino". (BLASI CUNHA, 2007, p. 104) 
Além destes espaços, os demais ambientes ocupados por Antônio também foram afetados: o posto de gasolina do Pontal e a Ilha da Convivência. Como é possível perceber no filme, o mar já avançava próximo ao posto, cuja destruição definitiva ocorre em abril de 1977. A Ilha, no entanto, viu sua população diminuir gradativamente ao longo do processo erosivo, até encontrar-se quase desabitada, nos dias de hoje.

Mesmo que a percepção atual nos faça imaginar que cada espaço enquadrado talvez não exista mais, o próprio filme já carrega em sua narrativa o sentimento de desaparecimento iminente. Há uma sequência em que isto é retratado de modo direto, para além das paisagens de destruição: os moradores tiram os móveis de casa às pressas e colocam no caminhão de mudança, fugindo do avanço do mar. Este aspecto é algo presente ainda hoje em Atafona - o que reitera a ideia de identificação, além do sentido de referência visual tanto para quem viveu o local nestes anos, quanto para quem não o conheceu da mesma maneira.

Em cenas como essa, Na Boca do Mundo assimila o povo de Atafona enquanto parte de sua expressão artística. Apesar da narrativa centrada nos três protagonistas, os atafonenses envolvem-se diretamente na construção visual deste espaço, presentes em diversos momentos: no bar, na missa, no incêndio da casa de pau a pique, na Ilha da Convivência, no Pontal. Nesse sentido, a participação dos habitantes do balneário evidencia a dimensão simbólica das imagens deste filme e sua compreensão enquanto lugar de memória - as imagens criam e devolvem "sinais em estado puro". A colaboração direta do povo atafonense consta também nos registros de $\mathrm{Na}$ Boca do Mundo, catalogado pela Cinemateca Brasileira. Dentre os nomes do elenco está presente: "Povo de Atafona". Da mesma maneira, o filme encerra com um agradecimento especial: "A todo povo de Atafona e da Ilha da Convivência".

\section{Recepção e preservação de Na Boca do Mundo}

De acordo com os registros da Cinemateca Brasileira, Na Boca do Mundo teve sua estreia em 22 de janeiro de 1979. O filme entra no circuito exibidor comercial seis dias depois, em dez salas de cinema do Rio de Janeiro. Neste primeiro semestre de 79, os cadernos de arte e lazer do jornal $O$ Globo apresentam algumas matérias sobre o lançamento do filme, com destaque para a coluna de Nelson Motta do dia 16 de janeiro, intitulada "Glauber apresenta Pitanga: 'Na Boca do Mundo'". 
A partir do dia 28 de janeiro de 1979, o caderno suplementar Rio Show, de O Globo, apresenta $\mathrm{Na}$ Boca do Mundo entre os filmes avaliados pelos críticos de cinema do jornal. Com base no tradicional sistema de cotações "O Bonequinho Viu", o filme teve recepção moderada, com o "Bonequinho" sentado assistindo - considerado como avaliação regular. "Neste seu filme de estreia como diretor de cinema o ator Antonio Pitanga consegue, através de uma narrativa simples e bem filmada, traduzir a verdade de seus personagens com emoção e equilíbrio".

Dentre as críticas negativas recebidas pelo filme, destaca-se o artigo de Zulmira Ribeiro Tavares publicado no periódico Filme Cultura n. ${ }^{\circ} 34$. A autora desdenha de $\mathrm{Na}$ Boca do Mundo por conta de diversos aspectos narrativos, mas, principalmente, condena 0 retrato das relações inter-raciais.

Trata-se de uma fita curiosa, viva e que interessa; mas o conjunto é ruim. Na Boca do Mundo, alinhava banalidades sobre a existência, escamoteia a realidade social de Atafona assim como das relações inter-raciais no Brasil; contudo não fica nisso; no seu corpo-a-corpo com a imagem, a câmera destaca falas e gestos que escapam à banalização do conjunto e insinuam um outro possível filme sob a pele do primeiro.(TAVARES, 1980, p. 27)

O texto condena, sobretudo, o desenvolvimento dos personagens Antônio e Terezinha, ao apontar incoerências em suas motivações. Ainda que reconheça qualidades estéticas no filme, principalmente "no plano do detalhe", a autora questiona a visão do preconceito racial no relacionamento dos personagens centrais - apontando representações que ela acredita serem desproporcionais e inverossímeis como encenadas por Pitanga.

Apesar da recepção negativa ou desinteressada de parte da crítica cinematográfica, $\mathrm{Na}$ Boca do Mundo foi bem aceito em outras oportunidades. Pola Vartuck, crítica do Estado de São Paulo, elogia a percepção de Pitanga diante da problemática racial, livre de maniqueísmos na construção das personagens. Nesse sentido, a crítica ressalta o desenvolvimento da personagem e Sibele Rúbia, uma vez que o filme "em nenhum momento tenta justificar o comportamento de Terezinha (embora tampouco condene) pelo fato de ter sido ditado pela miséria" ${ }^{\prime 5}$. Enfatiza, ainda, a aclamação ao trabalho de Pitanga.

Antonio Pitanga dirige o seu primeiro filme (no qual também desempenha o principal papel masculino) com uma segurança e fluidez raras num diretor estreante. De muito lhe valeu, naturalmente, a sua experiência como ator com 22 de anos de

\footnotetext{
${ }^{5}$ VARTUCK, Pola. Segurança e fluidez na direção de um estreante. O Estado de São Paulo, 21 de setembro de
} 1979. 
carreira, e a sua participação em vários clássicos do Cinema Novo, especialmente nos filmes de Glauber Rocha e Cacá Diegues. ${ }^{6}$

Vartuck sublinha o comentário de Glauber sobre Na Boca do Mundo, endossando a opinião do realizador. "Glauber Rocha, numa de suas frases brilhantes, diz que Pitanga, neste filme, denuncia que 'a sociedade branca mata negros por amor'". Em seu texto, publicado no jornal Correio Braziliense, Glauber comenta: "(...) Seu corpo é a macumba ao ritmo de Jorge Ben cantado por Caetano Veloso - conclui tribal. Pytanga é o milagre do artista negro 'antirracista'"'7. Ao mesmo tempo em que expõe sua admiração à "imagem tropykalyzta" de Pitanga, Glauber acentua a contestação a uma suposta democracia racial brasileira enquanto centro de sua crítica - a partir de referências históricas e artísticas.

A granfina drogada e mórbida vivida por Norma Bengell devora o negro, Lamour Sôvage e depois o mata, o queima, o cinzela nas memórias destruídas por Ruy Barbosa das senzalas que ainda perduram. O crime é verificado como acidente (ainda mais de um operário negro!!!) e o sexo é sequestrado pela colonizadora". ${ }^{8}$

Nesse sentido, Glauber compara o crime de Clarisse - ateando fogo à casa de Antônio, após envenená-lo - com a queima dos arquivos referentes à escravidão no Brasil, executado a mando do então ministro da Fazenda, Ruy Barbosa. O cineasta compara, ainda, a representação do mito do "bom selvagem", de Rousseau, com a maneira como Clarisse identifica Antônio, no sentido de parodiá-lo (Lamour Sôvage).

Na Boca do Mundo foi digitalizado e lançado em DVD pela Fundação Cultural Palmares (2006), em um compêndio intitulado: "Obras raras: o cinema negro da década de 70". Nesta coleção também estão Vida Nova por Acaso (1970), Compasso de Espera (1973), As Aventuras Amorosas de um Padeiro (1975) e A Deusa Negra (1978). Uma reportagem de $O$ Globo, em 2006, comenta o lançamento oficial dessa coletânea no dia 18 de dezembro, no cine Odeon, Centro do Rio de Janeiro. O texto cita, ainda, uma recepção favorável da crítica estrangeira à $\mathrm{Na} B o c a$ do $\mathrm{Mundo}^{9}$, bem como o projeto de Pitanga em realizar seu segundo filme, Malês, a partir de 2008 (ainda assim, Na Boca do Mundo permanece como único longa-metragem dirigido pelo ator).

Há poucos registros quanto à preservação física de cópias de Na Boca do Mundo. O filme está catalogado no arquivo da Cinemateca Brasileira, em São Paulo. Constam, no

\footnotetext{
${ }^{6}$ VARTUCK, Pola. Segurança e fluidez na direção de um estreante. O Estado de São Paulo, 21 de setembro de 1979

7 ROCHA, Glauber. Antonio Pitanga visto por Glauber Rocha. Correio Braziliense, 31 de janeiro de 1979.

${ }^{8}$ ROCHA, Glauber. Antonio Pitanga visto por Glauber Rocha. Correio Braziliense, 31 de janeiro de 1979.

${ }^{9} \mathrm{O}$ texto comenta os elogios que o jornal francês Le Monde concedeu a Na Boca do Mundo e à direção de Pitanga.
} 
registro do material original, os seguintes dados sobre formato: $35 \mathrm{~mm}$, "COR, 100min, 2.745m, 24q, Eastmancolor". No entanto, o setor de Catalogação da instituição aponta que a transcrição total de letreiros teria $3.300 \mathrm{~m}$, o que representa aproximadamente 20 minutos a mais de filme.

\section{Considerações finais}

Em sua trajetória no cinema brasileiro, Na Boca do Mundo encontra poucos paralelos. Como mencionado anteriormente, o filme é usualmente lembrado junto das obras de Waldir Onofre e Zózimo Bulbul, como parte da fase introdutória de um cinema negro nacional, nas décadas de 1970 e $1980^{10}$. Ainda o único longa-metragem dirigido por Pitanga, Na Boca do Mundo muitas vezes é esquecido ou mencionado apenas en passant quando se discute a carreira do ator e realizador baiano - até mesmo no documentário biográfico Pitanga (2017), dirigido por Beto Brant e Camila Pitanga, o filme de 1979 não é discutido.

Apesar de pouca repercussão, nota-se, através desta pesquisa, o significativo valor artístico de $\mathrm{Na}$ Boca do Mundo. Ao apresentar uma perspectiva singular diante das relações inter-raciais, o filme se destaca na cinematografia brasileira. Pela configuração arquetípica dos três protagonistas, surge uma percepção social distinta das obras contemporâneas já mencionadas, como As Aventuras Amorosas de Um Padeiro e Compasso de Espera. Nestes filmes, o homem negro é posicionado enquanto artista ou intelectual, enquanto Pitanga opta por um protagonista ex-pescador e frentista, que, como aponta Lapera, "se situava entre a submissão ao mundo dos brancos e a conquista pelo afeto" (LAPERA, 2012, p. 40).

Como aponta Orlando Senna, em Preto e Branco Ou Colorido, a estreia de Pitanga apresenta um realizador contundente e, sobretudo, que representa "uma conquista real, material, da Cultura Negra". Ainda sobre a importância e representatividade de Na Boca do Mundo, o autor complementa: "Vale enfatizar que este é o único meio para que um discurso Negro seja articulado no Cinema Brasileiro: a tomada, pelos próprios negros, de uma parcela de decisão na complexa engrenagem cinematográfica - capitalista, industrial e fechada". (SENNA, 1979, p. 226)

10 É importante destacar, ainda, a cineasta Adélia Sampaio como parte desta geração. Adélia dirigiu o longametragem Amor Maldito (1984). 
Presente em um pensamento crítico formador do cinema contemporâneo, como apontado pelo manifesto Dogma Feijoada (DE, 2005) e outros estudos da área, Antônio Pitanga também faz parte de um círculo de influências importantes para cineastas do Brasil. Ao analisar o cinema nacional contemporâneo, percebe-se um maior número de realizadores negros, com destaque para Joel Zito Araújo e Jeferson De. Atualmente, na direção de longas-metragens, surgem novos diretores como Viviane Ferreira (Um Dia com Jerusa, 2020), Glenda Nicácio (Café com Canela, 2018 ${ }^{11}$ ), André Novais (Temporada, 2019) e Gabriel Martins (No Coração do Mundo, 201912).

Além desta representatividade no panorama do cinema brasileiro, Na Boca do Mundo torna-se importante como registro histórico e memorial de Atafona. No filme de Pitanga, a locação não é apenas pano de fundo para os personagens, como também um universo real e simbólico, tomado de sentido pelo próprio povo atafonense. Retomando a visão de Pierre Nora, constatamos que os lugares de memória garantem a materialização de narrativas históricas, bem como a transferência de experiências entre diversas gerações. Nesses registros, os grupos retratados - como ocorre em Na Boca do Mundo, com Atafona e seu povo - permanecem carregados de simbolismo e de uma trajetória transformadora.

Porque, se é verdade que a razão fundamental de ser de um lugar de memória é parar o tempo, é bloquear o trabalho do esquecimento, fixar um estado das coisas, imortalizar a morte, materializar o imaterial para (...) prender o máximo de sentido num mínimo de sinais, é claro, e é isso que os torna apaixonantes: que os lugares de memória só vivem de sua aptidão para a metamorfose, no incessante ressaltar de seus significados e no silvado imprevisível de suas ramificações. (NORA, 1993. p. 22).

Neste artigo, portanto, Na Boca do Mundo é compreendido enquanto um retrato que não se mantém apenas na paisagem destruída de Atafona ou na condição de pobreza dos locais. O filme sintetiza o imaginário de uma região e de uma época específica, na medida em que se torna um lugar de memória, sempre significativo para quem o revisita - tendo ou não relação prévia com Atafona. Ainda que pouco mencionado na historiografia do cinema brasileiro, $\mathrm{Na} B o c a$ do Mundo pode ser reconhecido enquanto obra expressiva de um período de transformações sociais e raciais no país. Ao ser revisitado, o filme mantém o aspecto crítico e, sobretudo, um olhar sintomático sobre questões que ainda perduram e articulam-se diretamente na atualidade - revelando uma narrativa (e uma construção imagética) de sociedade que permanece em disputa.

\footnotetext{
11 filme co-dirigido por Ary Rosa.

12 filme co-dirigido por Maurílio Martins.
} 


\section{Referências bibliográficas}

AMANCIO, Tunico. Pacto cinema-Estado: os anos Embrafilme. Revista ALCEU/ PUC-Rio, v. 8 - n.15 - p. 173 a 184 - jul./dez. 2007.

ANDERSON, Benedict. Comunidades imaginadas: reflexões sobre a origem e difusão do nacionalismo. São Paulo: Companhia das Letras, 2008.

BLASI CUNHA, Juliana. Atafona: formas de sociabilidade em um balneário na região Norte Fluminense. Dissertação apresentada ao Programa de Pós-graduação em Antropologia, do Instituto de Ciências Humanas e Filosofia, UFF. Niterói, 2007. CARVALHO, Noel dos Santos; DOMINGUES, Petrônio. A representação do negro em dois manifestos do cinema brasileiro. Estudos avançados, vol. 31 n. ${ }^{\circ} .89$, São Paulo, jan.abr./2017.

DAMATTA, R. Relativizando: uma introdução à antropologia social. Rio de Janeiro, Rocco, 1987.

DE, JEFERSON. Dogma Feijoada: O cinema Negro Brasileiro. São Paulo. Imprensa Oficial do Estado de São Paulo: Cultura - Fundação Padre Anchieta, 2005. p.: il. - (Coleção Aplauso. Série cinema Brasil / coordenador geral Rubens Ewald Filho).

FUNDAÇÃO CULTURAL PALMARES. "Obras raras: o cinema negro da década de 70", Brasília, 2006.

GATTI, André Piero. Embrafilme e o cinema brasileiro. São Paulo, Centro Cultural de São Paulo. 2008.

GOMES, Renan da Silva. A ILHA, o MAR e a "CIDADE DEBAIXO D'ÁGUA": paisagens e mudanças ambientais em Atafona - RJ. Dissertação de Mestrado apresentada ao Programa de Pós-Graduação em Geografia (PPGG), UFRJ. Rio de Janeiro, 2012. JORGE, Marina Soler. Cinema Novo e Embrafilme: Cineastas e Estado pela consolidação da indústria cinematográfica Brasileira. Dissertação de mestrado apresentada ao Departamento de Sociologia da Unicamp, 2002.

LAPERA, P.V.A. Do preto-e-branco ao colorido: raça e etnicidade no cinema brasileiro dos anos 1950-70. Tese (Doutorado em Comunicação) - Universidade Federal Fluminense, Instituto de Arte e Comunicação Social, 2012.

. Por uma sexualidade tropical-radical: raça, imaginação nacional e intelectuais negros no cinema brasileiro dos anos 1970. Trabalho apresentado na mesa "Questões de representação", XVII Encontro da Socine, Unisul - Palhoça, 2013. NORA, Pierre. Entre memória e história: a problemática dos lugares. Projeto História, São Paulo: PUC-SP, n. 10, p. 9, p. 21-22. 1993.

PENNA, G. O. Que mulata é essa? As ilustrações de Alceu Penna para o show Brasil Export (1972). DOBRAS (BARUERI, SP), v. 9, p. 94-115, 2016. 
PINTO, João Alberto da Costa. Gilberto Freyre e o Lusotropicalismo como ideologia do Colonialismo português (1951-1974). Revista UFG, Ano XI nº 6. 2009.

SENNA, Orlando. Preto e branco ou colorido: o negro no cinema brasileiro. Petrópolis: Revista de Cultura Vozes, 1979.

STAM, Robert. Multiculturalismo tropical: Uma história comparativa da raça na cultura e no cinema brasileiros. São Paulo, EDUSP, 2008.

TAVARES, Zulmira Ribeiro. Narrativa e Imagem. Filme Cultura n.o 34, pp. 27-28.

Embrafilme, jan.-abr./1980.

XAVIER, ISMAIL. O cinema brasileiro moderno. 1. ed. São Paulo: Paz e Terra, 2001. 